\title{
Factors affecting platinum sensitivity in cervical cancer
}

\author{
RINA KATO $^{1,2}$, KIYOSHI HASEGAWA ${ }^{3}$, YUTAKA TORII ${ }^{2}$, YASUHIRO UDAGAWA ${ }^{2,3}$ and ICHIO FUKASAWA $^{3}$ \\ ${ }^{1}$ Department of Obstetrics and Gynecology, Tokyo Medical University, Tokyo 160-0023; \\ ${ }^{2}$ Department of Obstetrics and Gynecology, School of Medicine, Fujita Health University, Toyoake, Aichi 470-1192; \\ ${ }^{3}$ Department of Obstetrics and Gynecology, Dokkyo Medical University, Mibu, Tochigi 321-0293, Japan
}

Received October 12, 2014; Accepted August 17, 2015

DOI: $10.3892 / \mathrm{ol} .2015 .3755$

\begin{abstract}
The present study aimed to investigate the association between nedaplatin (NDP) sensitivity and the expression of biological factors in cervical cancer. A total of 45 cervical cancer specimens, including 18 pretreatment biopsies and 27 surgical specimens, were used in histoculture drug response assays to determine the chemosensitivity of cervical cancer specimens to NDP. Each specimen was assessed for immunohistochemical expression of Ki-67, p53, B-cell lymphoma-2 (Bcl-2), Bcl-2-associated $\mathrm{X}$ protein (Bax), cleaved caspase-3, cyclooxygenase-2 (COX-2), and excision repair cross-complementation group 1 (ERCC1). The results revealed that low or negative expression of p53, Bcl-2 and COX-2, and high or positive expression of cleaved caspase-3 were significantly correlated with high sensitivity to NDP. However, there were no significant differences in Ki-67, Bax or ERCC1 expression between the low and high sensitivity groups. These findings indicate that sensitivity to platinum may be easily predicted by immunostaining for the detection of these specific factors in pretreatment biopsies or surgical specimens. The expression profiles of these targets may therefore provide additional information for planning individualized chemotherapy in the treatment of cervical cancer.
\end{abstract}

\section{Introduction}

Cervical cancer is the fourth most common cancer in women, and the seventh overall, with an estimated 528,000 new cases in 2012. There were an estimated 266,000 mortalities from cervical cancer worldwide in 2012 , accounting for $7.5 \%$ of all female cancer mortalities. Around $87 \%$ of mortalities from cervical cancer occur in less developed regions (1).

Guidelines for the treatment of uterine cervical cancer, based on the results of randomized controlled trials, have been published by the National Comprehensive Cancer Network (2)

Correspondence to: Dr Kiyoshi Hasegawa, Department of Obstetrics and Gynecology, Dokkyo Medical University, 880 Kitakobayashi, Mibu, Tochigi 321-0293, Japan

E-mail: hasek@dokkyomed.ac.jp

Key words: cervical cancer, chemosensitivity, platinum, nedaplatin, biological factors and National Cancer Institute (3). For early-stage cervical cancer, the first-line treatment consists of radical surgery alone or in combination with adjuvant radiotherapy, while concurrent chemoradiotherapy with cisplatin may also be used as an adjuvant therapy in cases of high-risk early-stage cervical cancer, particularly those positive for lymph node metastasis. Chemoradiotherapy is also recommended in cases of locally advanced cancer (3). However, with the exclusion of chemoradiotherapy, the role of chemotherapy as a treatment for uterine cervical cancer has not been clearly established.

In cases involving distant metastasis or recurrence, chemotherapy consisting of cisplatin combined with paclitaxel is currently considered to be among the most effective regimens, based on findings from a randomized controlled study (4). In addition, for cases of intermediate- and high-risk, early-stage disease, the postoperative use of cisplatin-based chemotherapy has demonstrated some degree of clinical efficacy (5-8). However, chemotherapeutic protocols for cervical cancer have are poorly defined at present; in order to establish the effect of chemotherapy on clinical outcome in cases of cervical cancer, large-scale clinical trials are necessary. Furthermore, it is important to establish which factors may be used to predict and alter chemosensitivity to cisplatin to facilitate the individualization of treatment and inform clinical decisions.

We have previously studied the chemosensitivity of the platinum analog nedaplatin (NDP) using the histoculture drug response assay (HDRA; see methods) (9). The sensitivity of cervical cancers to NDP was predicted by the HDRA; the true positive rate was determined to be $100 \%$, whilst the true negative rate was $55.6 \%$ and the accurate prediction rate was $77.8 \%$. Furthermore, the disease-free survival rate for the high-sensitivity group was generally higher compared with that of the low-sensitivity group in patients who received postoperative adjuvant chemotherapy with NDP (9). Thus, NDP is associated with a high response rate in cervical cancers that is comparable to the response rate achieved with cisplatin. In addition, NDP has fewer gastrointestinal side effects, is less nephrotoxic and requires less additional fluid during infusion $(10,11)$. For this reason, NDP has been widely used in Japan for the treatment of cervical cancer and was the agent selected for the present HDRA chemosensitivity analysis.

With the current trend of individualizing chemotherapy treatment protocols, studies must consider the various factors that predict and affect chemosensitivity in a given tumor. Establishing more information with regard to these factors may 
allow prediction of the chemosensitivity of cervical cancer in routine clinicopathological tests without using HDRA, and individualized chemotherapy may become clinically feasible in the treatment of cervical cancer.

The current study investigated the association between NDP sensitivity and the expression of biological factors affecting chemosensitivity, including the cell proliferation marker protein $\mathrm{Ki}-67$, apoptosis-related factors [p53, B-cell lymphoma-2 (Bcl-2), Bcl-2-associated X protein (Bax), cleaved caspase-3, and cyclooxygenase-2 (COX-2)] and the nucleotide excision repair-related protein excision repair cross-complementation group 1 (ERCC1), in cervical cancer specimens using immunohistochemistry.

\section{Materials and methods}

Subjects. The current study was performed as an extension of our previous study, and patient characteristics and the study design are described elsewhere (9). A total of 179 patients with invasive cervical squamous cell carcinoma were treated between April 2002 and August 2009 at Fujita Health University Hospital (Toyoake, Japan). Among these 179 patients, 45 with International Federation of Gynecology and Obstetrics (FIGO) stage IB1-IVB disease were enrolled in the study after providing informed consent. The median age of patients was 46 years (range, 30-67 years). Clinical FIGO stages were as follows: Stage IB1, 12 patients; stage IB2, 3 patients; stage IIA, 6 patients; stage IIB, 16 patients; stage IIIA, 1 patient; stage IIIB, 4 patients; and stage IVB, 3 patients. HDRA was performed on 18 pretreatment biopsies and 27 surgical specimens obtained from these patients to determine the chemosensitivity of cervical cancer to NDP. The HDRA procedure was described previously (12). Briefly, collagen gel sponge (Gelform, Pfizer, USA) was cut into $\sim 1 \mathrm{~cm}^{3}$ cubes and placed into the wells of a 24-well plate. The concentration of NDP in the medium was set at $6.25,12.5,25,50$ and $100 \mu \mathrm{g} / \mathrm{ml}$. Specimens were washed and cut into $\sim 1 \mathrm{~mm}^{3}$ pieces in medium ( $1 \mathrm{ml} /$ well), and placed on the collagen gel sponge. Specimens were then cultured for 7 days. Following incubation, cell viability was assessed using an MTT assay to identify the concentration that produced $50 \%$ inhibition of tumor growth $\left(\mathrm{IC}_{50}\right)$. The optimal cut-off value of NDP was set at $48 \mu \mathrm{g} / \mathrm{ml}$ based on the $\mathrm{IC}_{50}$ of NDP determined in our previous study (9); cases with an $\mathrm{IC}_{50}$ below or above the cut-off concentrations were defined as having high or low sensitivity to NDP, respectively.

Immunohistochemistry. Immunohistochemical staining was performed using the avidin-biotin-peroxidase complex method for 18 pretreatment biopsies and 27 surgical specimens. Briefly, formalin-fixed, paraffin-embedded sections were deparaffinized, rehydrated, and treated with $3 \% \mathrm{H}_{2} \mathrm{O}_{2}$ in methanol to block endogenous peroxidase activity. Following antigen retrieval in a microwave oven with $10 \mathrm{mM}$ citrate buffer (pH 6.0; Cosmo Bio Co., Ltd., Tokyo, Japan) at $90^{\circ} \mathrm{C}$, the sections were incubated overnight with primary antibodies at $4{ }^{\circ} \mathrm{C}$, followed by incubation with biotinylated goat anti-mouse IgG (cat. no. BA-9200) or goat anti-rabbit IgG (cat. no. BA-1000) secondary antibodies (Vector Laboratories, Inc., Burlingame, CA, USA). Staining was visualized using avidin-biotin-peroxidase complex solution (Vectastain
ABC kit, Vector Laboratories, Inc.) and 3,3'-diaminobenzidine $-\mathrm{H}_{2} \mathrm{O}_{2}$ solution, and counterstaining with hematoxylin was conducted.

Primary antibodies against human Ki-67 (MIB-1; mouse monoclonal; cat. no. N1653; dilution, 1:100; Dako, Glostrup, Denmark), p53 (DO-7; mouse monoclonal; cat. no. N1581; dilution, 1:100; Dako), Bcl-2 (124; mouse monoclonal; cat. no. 713141; dilution, 1:1; Nichirei Biosciences, Inc., Tokyo, Japan), Bax (B-9; mouse monoclonal; cat. no. sc-7480; dilution, 1:100; Santa Cruz Biotechnology, Inc., Santa Cruz, CA, USA), cleaved caspase-3 (Asp175; mouse monoclonal; cat. no. 9661S; dilution, 1:400; Cell Signaling Technology, Danvers, MA, USA), COX-2 (rabbit monoclonal; cat. no. 18516; dilution, 1:50; Immuno-Biological Laboratories Co., Ltd., Fujioka, Japan) and ERCC1 (8F1; mouse monoclonal; cat. no. MA5-13912; dilution, 1:100; Thermo Fisher Scientific, Waltham, MA, USA) were used. The primary antibody was omitted for the negative control. For positive controls, sections known to overexpress each protein from the initial study were always run.

Immunostaining for Bcl-2, Bax and COX-2 was graded according to immunohistochemical score; scores from 0-18 were determined by the multiplication of scores for frequency (scored from 1-6) and intensity (scored from 0-3) of staining (12). Staining frequency was scored based on the proportion of positively staining cells as follows: $1,0-4 \% ; 2,5-19 \% ; 3,20-39 \% ; 4,40-59 \% ; 5,60-79 \%$; or $6,80-100 \%$. Staining intensity was scored as 0 (negative), 1 (weak), 2 (moderate) or 3 (strong). Cases having a score $>2$ were defined as positive in the current study. Evaluation of immunostaining for ERCC1 was graded according to immunohistochemical score as described by Kim et al (13); scores ranged from $0-9$ and were determined by multiplying the scores for staining frequency $(0,0 \% ; 1,0-9 \% ; 2,10-49 \%$; $3,50-100 \%$ ) and intensity (scored from $0-3$, as above). Based on immunoreactivity, samples with scores of $\geq 4$ were defined as positive in this study. For Ki-67 and p53, the percentage of immunostained tumor cells from 10 fields that showed relatively higher expression levels throughout the tumor was employed as the labeling index (LI) to evaluate the expression level. For cleaved caspase-3, the number of positively stained cells per 1000 tumor cells exhibiting the highest level of expression on the section was designated as the apoptotic index (AI) and was used to evaluate apoptotic cells.

Evaluations were performed by two gynecological oncologists, neither of whom had knowledge of any clinical information related to the cases.

Statistical analysis. All measured values were represented as the mean \pm standard deviation and were analyzed by Student's $t$-test and Fisher's exact test. SPSS software version 12.0 (SPSS, Inc., Chicago, IL, USA) was used to conduct the analyses. $\mathrm{P}<0.05$ was considered to indicate statistical significance.

\section{Results}

NDP chemosensitivity of 45 patients with cervical cancer. Using $\mathrm{IC}_{50}$ values below or above the cut-off concentration to define high or low sensitivities to NDP, respectively (9), 
Table I. Expression levels of various proteins in high and low nedaplatin sensitivity groups.

\begin{tabular}{lccc}
\hline & \multicolumn{3}{c}{ Nedaplatin sensitivity } \\
\cline { 2 - 4 } Factor & High $(\mathrm{n}=17)$ & Low (n=28) & 0.428 \\
\hline Ki-67 LI, $\%$ & $43.9 \pm 20.0$ & $47.4 \pm 18.7$ & 0.002 \\
p53 LI, \% & $14.1 \pm 10.5$ & $28.2 \pm 18.6$ & 0.002 \\
Bcl-2 score & $1.1 \pm 1.5$ & $3.9 \pm 3.3$ & 0.632 \\
Bax score & $1.8 \pm 2.3$ & $1.2 \pm 1.5$ & 0.021 \\
Cleaved caspase-3 AI & $29.4 \pm 18.6$ & $17.1 \pm 10.6$ & 0.041 \\
COX-2 score & $2.6 \pm 2.2$ & $4.7 \pm 3.2$ & 0.399 \\
ERCC1 score & $3.4 \pm 1.9$ & $4.7 \pm 3.2$ & \\
\hline
\end{tabular}

Data are presented as mean \pm standard deviation. Bcl-2, B-cell lymphoma-2; Bax, Bcl-2-associated X protein; COX-2, cyclooxygenase-2; ERCC1, excision repair cross-complementation group 1; LI, labeling index; AI, apoptotic index (per 1000).

Table II. Association between expression of various proteins and nedaplatin sensitivity.

\begin{tabular}{|c|c|c|c|c|}
\hline \multirow[b]{2}{*}{ Factor } & \multirow[b]{2}{*}{ Patients, $\mathrm{n}$} & \multicolumn{2}{|c|}{ Nedaplatin sensitivity, $\mathrm{n}$} & \multirow[b]{2}{*}{ P-value } \\
\hline & & $\operatorname{High}(n=17)$ & Low $(n=28)$ & \\
\hline Ki-67 LI, \% & & & & 0.608 \\
\hline$<40$ & 19 & 8 & 11 & \\
\hline$\geq 40$ & 26 & 9 & 17 & \\
\hline p53 LI, \% & & & & 0.009 \\
\hline$<30$ & 29 & 15 & 14 & \\
\hline$\geq 30$ & 16 & 2 & 14 & \\
\hline Bcl-2 & & & & 0.0008 \\
\hline Negative & 20 & 13 & 7 & \\
\hline Positive & 25 & 4 & 21 & \\
\hline Bax & & & & 0.608 \\
\hline Negative & 26 & 9 & 17 & \\
\hline Positive & 19 & 8 & 11 & \\
\hline Cleaved caspase-3 AI & & & & 0.016 \\
\hline$<40$ & 41 & 13 & 28 & \\
\hline$\geq 40$ & 4 & 4 & 0 & \\
\hline $\mathrm{COX}-2$ & & & & 0.023 \\
\hline Negative & 6 & 5 & 1 & \\
\hline Positive & 39 & 12 & 27 & \\
\hline ERCC1 & & & & 0.079 \\
\hline Negative & 19 & 10 & 9 & \\
\hline Positive & 26 & 7 & 19 & \\
\hline
\end{tabular}

Bcl-2, B-cell lymphoma-2; Bax, Bcl-2-associated X protein; COX-2, cyclooxygenase-2; ERCC1, excision repair cross-complementation group 1; LI, labeling index; AI, apoptotic index (per 1000).

17 cases were classified into the high-sensitivity group and the remaining 28 cases were classified into the low-sensitivity group.

Association between chemosensitivity and the expression of various proteins. The typical protein expression of seven biological factors evaluated in this study is presented in Fig. 1. The associations between chemosensitivity to NDP and expression of these seven factors are described in Tables I and II. The analysis revealed that the relative expression levels of p53 (LI), Bcl-2 (score), cleaved caspase-3 (AI) and COX-2 (score) in the high-sensitivity group versus the low-sensitivity group were as follows: p53, 14.1 \pm 10.5 vs. $28.2 \pm 18.6$; Bcl-2, $1.1 \pm 1.5$ vs. $3.9 \pm 3.3$; cleaved caspase-3, 

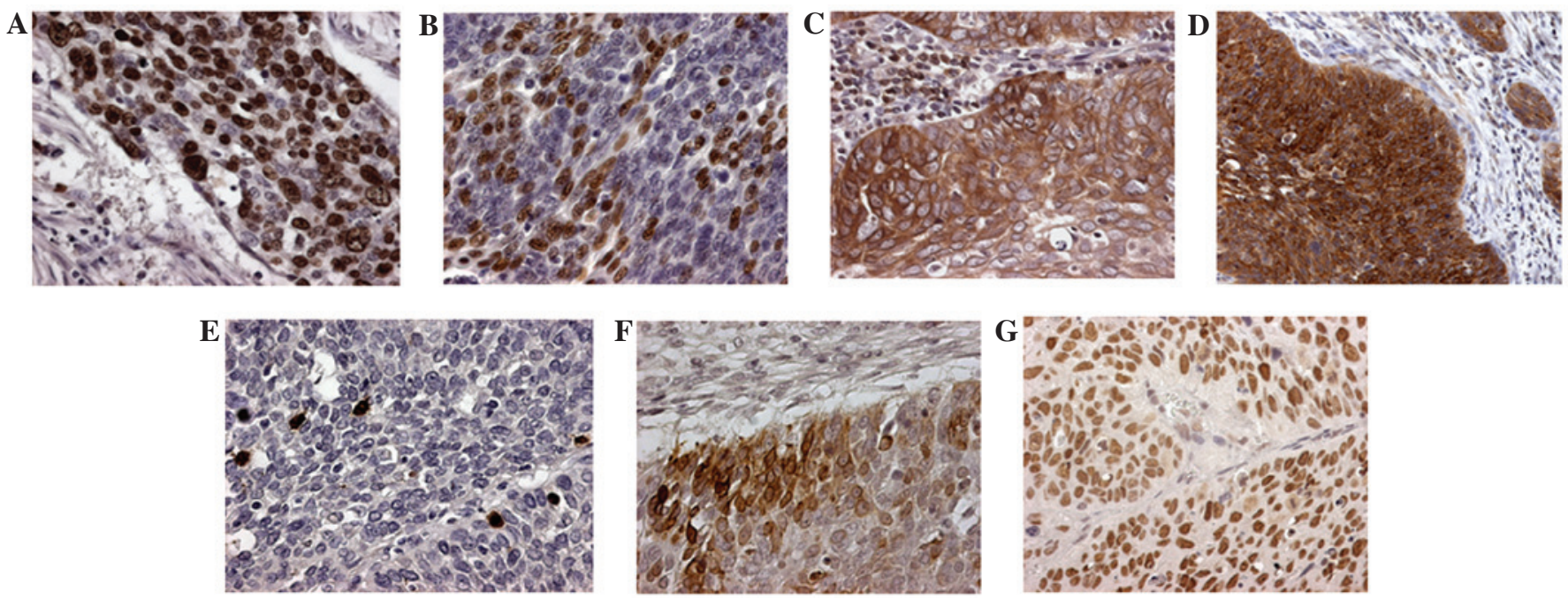

Figure 1. Typical protein expression of seven biological factors evaluated in the present study, observed by immunohistochemistry (original magnification, x200). (A) Ki-67 (LI, 75\%); (B) p53 (LI, 39\%); (C) B-cell lymphoma-2 (score, 8); (D) Bcl-2-associated X protein (score, 6); (E) cleaved caspase-3 (AI, 38.6); (F) cyclooxygenase-2 (score, 15); (G) excision repair cross-complementation group 1 (score, 9). LI, labeling index; AI, apoptotic index (per 1000).

$29.4 \pm 18.6$ vs. $17.1 \pm 10.6$; and COX-2, $2.6 \pm 2.2$ vs. $4.7 \pm 3.2$ (Table I). The expression levels of these four factors differed significantly between the high- and low-sensitivity groups ( $\mathrm{P}=0.002,0.002,0.021$, and 0.041 , respectively). However, no significant differences in the expression levels of Ki-67 (LI), Bax (score) or ERCC1 (score) were observed between the high- and low-sensitivity groups (Table I).

Furthermore, using cut-off values able to significantly distinguish between high and low expression groups, a p53 LI of $<30(n=29)$ was significantly associated with high NDP sensitivity ( $\mathrm{P}=0.009$; Table II), as was a cleaved caspase-3 AI $\geq 40(\mathrm{n}=4 ; \mathrm{P}=0.016)$. Patients with negative immunostaining of Bcl-2 $(\mathrm{n}=20)$ and $\mathrm{COX}-2(\mathrm{n}=6)$ were also significantly more sensitive to NDP ( $\mathrm{P}=0.0008$ and 0.023 , respectively). For ERCC1, patients with negative immunostaining $(n=19)$ tended to be more sensitive to NDP $(\mathrm{P}=0.079)$; however, this difference was not significant (Table II).

\section{Discussion}

HDRA, developed by Hoffman et al $(14,15)$ in 1991, and improved by Ohie et al (16) in 2000, resembles an in vivo assay as it supports three-dimensional proliferation on a collagen gel matrix. The advantages of HDRA are that it has a high evaluation rate, permits the prompt acquisition of results, correlates with clinical responses, allows for the testing of multiple anticancer drugs and is relatively inexpensive.

A number of clinical studies using HDRA have demonstrated that it has a high evaluation rate or accuracy in a number of tumor types, including non-small cell lung cancer (17), esophageal cancer (18), stomach and colorectal cancer (19), breast cancer $(20,21)$, urothelial cancer (22), head and neck cancer (23) and soft tissue sarcoma (24). In gynecological cancers, the accurate prediction rates of sensitivity to platinum were $83 \%$ and $87.5 \%$ in ovarian and endometrial cancers, respectively $(25,26)$. Additionally, a correlation between chemosensitivity to platinum and prognosis in endometrial cancer has been observed (26). Furthermore, in our previous study, the evaluation rate of HDRA was $94.0 \%$, with a true positive rate of $100 \%$, true negative rate of $55.6 \%$ and accurate prediction rate of $77.8 \%$ in cervical cancer (squamous cell carcinoma). Additionally, disease-free survival in the high-sensitivity group tended to be higher compared with that of the low-sensitivity group in patients who received postoperative adjuvant chemotherapy with NDP (9).

In the current study, we investigated whether the expression levels of Ki-67, p53, Bcl-2, Bax, cleaved caspase-3, COX-2, and ERCC1 were associated with chemosensitivity to NDP, as evaluated by HDRA, in cervical cancer. Identification of factors associated with NDP sensitivity may potentially facilitate the prediction of platinum sensitivity by immunohistochemistry in pretreatment biopsies or surgical specimens, which would be easier than using HDRA.

In general, tumors that have high proliferative activity are more sensitive to chemotherapeutic drugs or radiation compared with tumors that have low proliferative activity. This association between tumor proliferative activity and response to chemotherapy has been reported in breast cancer $(27,28)$. Additionally, in cervical cancer, Sultana et al (29) reported that high expression of $\mathrm{Ki}-67$ in preoperative biopsies was associated with the clinical response to platinum-containing neoadjuvant chemotherapy and improved prognosis. On the other hand, Costa et al (30) reported that there was no correlation between Ki-67 expression and clinical response to neoadjuvant chemotherapy or prognosis. In the current study, no association was identified between expression of Ki-67 and sensitivity to NDP, as evaluated by HDRA, consistent with the findings of Costa $e t$ al. However, the number of patients recruited in these studies, including the present study, was relatively small; therefore, further studies must be conducted with larger numbers of patients to confirm this association.

Platinum-induced apoptosis in tumor cells is generally dependent on the p53 pathway. However, when tumors possess P53 mutations, platinum does not induce apoptosis as effectively, and the clinical effects of platinum are restricted accordingly. Studies have demonstrated that patients with advanced ovarian 
cancer harboring P53 mutations or P53 overexpression exhibit low sensitivity to cisplatin-containing chemotherapy $(31,32)$. The rate of $P 53$ mutation in cervical cancer has been reported to be $<10 \%$, which is lower than that in certain other types of cancers (33). However, the relationship between P53 mutations and human papillomavirus (HPV) has not been clearly defined (34). In the current study, high-risk type HPV infections were also evaluated in 22 of 45 specimens; these specimens were frozen and adequately stored, allowing them to be used for polymerase chain reaction (PCR)-restriction fragment length polymorphism analysis. From this analysis, high-risk type HPV infections were identified in 19 of 22 specimens $(86.4 \%$; data not shown). Furthermore, in the same 22 specimens, only $2(9.1 \%)$ were found to possess P53 mutations (exons 5 and 6 ) by PCR-single strand conformation polymorphism (data not shown). This indicates that P53 mutations are relatively infrequent in cervical cancer compared with other types of cancer. Additionally, the rate of p53 protein overexpression has been reported to be $20-85 \%$ (33). p53 protein overexpression is not fully explained by P53 mutations, and several mechanisms have been proposed for this discrepancy (35-37); however, the precise reasons for $\mathrm{p} 53$ overexpression, including HPV integration, have not been proven.

In addition, the association between p53 overexpression and radiation sensitivity or sensitivity to platinum-containing chemotherapy have not been clearly defined in cervical cancer. Sultana et al (29) reported that there was no correlation between p53 expression in tumors and the clinical effects of platinum-containing chemotherapy. In the current study, a significant difference in $\mathrm{p} 53$ expression (LI) was observed between the high- and low-NDP sensitivity groups. Furthermore, patients with p53 LIs of $<30 \%$ were significantly more sensitive to NDP; therefore, these data suggest that the p53 LI may be utilized as a parameter for the easy prediction of platinum sensitivity using pretreatment biopsies or surgical specimens without requiring HDRA.

$\mathrm{Bcl}-2$ is an oncogene that inhibits radiation- or chemotherapy-induced apoptosis (38). Cervical cancers with Bcl-2 expression have been reported to exhibit radiation resistance and poor prognoses (39-41). However, contradictory results have also been found in terms of Bcl-2 expression and patient prognosis (42-49). Furthermore, in one study, no significant association was observed between Bcl-2 expression and the clinical effects of neoadjuvant chemotherapy (29). Thus, the association between Bcl-2 expression and chemosensitivity/radiosensitivity or prognosis has not been precisely defined. In the current study, a significant difference in Bcl-2 expression was observed between the high- and low-sensitivity groups. Additionally, tumors that were positive for Bcl-2 expression exhibited low sensitivity to platinum. However, because few studies have examined the relationship between $\mathrm{Bcl}-2$ expression and chemosensitivity, further studies are necessary to clarify this relationship with larger numbers of patients.

Bax is a member of the Bcl-2 family and plays a role in the p53-Bax pathway, which enhances apoptosis. In cervical cancer patients treated by radiotherapy alone, patients with Bax-positive tumors have been demonstrated to have a higher sensitivity to radiotherapy compared with those with Bax-negative tumors (50). Additionally, Bax expression in tumors may be used to predict radiosensitivity in these tumors (50). On the other hand, few studies have reported the association between Bax expression and the effects of chemotherapy. In one such study, Sultana et al (29) observed an association between Bax expression in preoperative biopsies of cervical cancer and the response rate to neoadjuvant chemotherapy.

In the current study, no association was found between Bax expression and NDP sensitivity in cervical cancer specimens. However, in cervical cancer, p53 function may be inactivated by HPV integration; therefore, various aspects of the p53-Bax pathway may be maintained in cervical tumors, and these mechanisms require additional investigation.

Caspase-3, a member of the caspase family, is expressed in its active form in apoptotic cells and acts at the final step of apoptosis. Therefore, immunohistochemistry using anti-cleaved caspase- 3 antibodies may be a relatively convenient method to detect apoptotic cells (51). In cervical cancer, a number of studies have reported that a high AI in pretreatment specimens (so-called spontaneous AI) is correlated with reduced efficacy of radiotherapy (52-54). In general, high AI in tumors is associated with intratumoral hypoxia, which in turn may decrease radiosensitivity. However, there has been no consensus on the association between intratumoral spontaneous AI and radiosensitivity due to differences in tumor histology, intratumoral distribution of hypoxia and cellular proliferative activity. On the other hand, Sultana et al (29) reported that spontaneous AI in pretreatment specimens was not correlated with the clinical effect of neoadjuvant chemotherapy. In the current study, higher expression of cleaved caspase-3 (AI) was significantly correlated with chemosensitivity to NDP. Therefore, the expression of cleaved caspase-3 may also permit detection of NDP chemosensitivity in cancer. Future studies should investigate the association between spontaneous AI and chemosensitivity or radiosensitivity.

The role of COX-2 in the development and progression of various types of cancer has been previously described. COX-2 overexpression is associated with the proliferation of tumor cells, inhibition of apoptosis, production of growth factors, increased activity in neoangiogenesis and invasion, and impairment of host immune responses (55-59). In particular, numerous studies have revealed that tumors exhibiting high expression levels of COX-2 protein have reduced responses to chemotherapy and poor prognoses; this is thought to occur because COX-2 inhibits apoptosis by inducing $\mathrm{Bcl}-2$ expression or reducing intratumoral ceramide concentrations, which play important roles in apoptosis (60). In cervical cancer, Ferrandina et al (61) reported that COX-2-positive cases were resistant to cisplatin and had unfavorable prognoses compared to that in COX-2-negative cases. In the current study, patients with negative COX-2 immunostaining were significantly more sensitive to NDP. These data suggested that COX-2 expression affected sensitivity to platinum in cervical cancer. Additionally, as $\mathrm{COX}-2$ induces $\mathrm{Bcl}-2$ expression (60), the association between COX-2 and $\mathrm{Bcl}-2$ expression was also investigated. However, a significant correlation between these factors was not observed (data not shown).

ERCC1 is involved in nucleotide excision repair and has been demonstrated to form a heterodimer with xeroderma pigmentosum-F (XPF). ERCC1/XPF complexes are responsible for an incision that cleaves the damaged nucleotide strand at the $5^{\prime}$ end of the lesion (62). Therefore, ERCC1 has a key role in mediating the response to a range of DNA-damaging 
chemotherapeutic agents. Evidence has suggested that increased expression of ERCC1 protein and mRNA are associated with resistance to platinum, and may be prognostic indicators of poor patient survival following treatment with platinum-based chemotherapy or chemoradiotherapy in various types of malignant neoplasms (63-71).

Park et al (71) reported that evaluating expression levels of ERCC1 protein in pretreatment specimens of FIGO stage IIB uterine cervical cancer may allow the prediction of response to cisplatin-based neoadjuvant chemotherapy; low ERCC1 expression was also reported to be a significant favorable prognostic indicator of disease-free survival. Our previous retrospective study indicated that immunostaining for ERCC1 expression may be useful for predicting survival in patients with uterine cervical adenocarcinoma being treated with platinum-based chemotherapy or chemoradiotherapy with cisplatin (72). Unexpectedly, in the current study, no significant association was identified between ERCC1 expression and NDP sensitivity in cervical cancer (squamous cell carcinoma). However, ERCC1-positive cases tended to exhibit low sensitivity to NDP. Thus, the association between ERCC1 expression and chemosensitivity to platinum will likely be clarified when further investigations with large numbers of patients are conducted.

In conclusion, the results of the present study indicated that $\mathrm{p} 53, \mathrm{Bcl}-2$, cleaved caspase-3, and COX-2 were biological factors affecting NDP sensitivity in cervical cancer. Low or negative expression of p53, Bcl-2, and COX-2, and high or positive expression of cleaved caspase- 3 were significantly associated with high sensitivity to NDP. Furthermore, negative ERCC1 expression may also be correlated with high sensitivity to NDP. Therefore, sensitivity to platinum can be easily predicted by immunostaining for these factors using pretreatment biopsies or surgical specimens. The expression profiles of these proteins may provide additional information for planning individualized chemotherapy in patients with uterine cervical cancer. In addition, a number of other biological factors affecting platinum sensitivity have been reported (73-75), and further evaluations should be conducted in the future. As more factors are tested and incorporated into screening panels, individualized chemotherapy, designed to maximize treatment response, may become clinically feasible in cervical cancer.

\section{References}

1. World Health Organization; International Agency for Research on Cancer: Cervical Cancer - Estimated Incidence, Mortality and Prevalence Worldwide in 2012. http://globocan.iarc.fr/Pages/ fact_sheets_cancer.aspx?cancer=cervix.

2. National Comprehensive Cancer Network: NCCN Clinical Practice Guidelines in Oncology (NCCN Guidelines). Cervical Cancer. Version 1.2013. http://www.alabmed.com/uplo adfile/2014/0221/20140221105002791.pdf. Accessed September 11,2015.

3. National Cancer Institute: Cervical cancer treatment. http://www. cancer.gov/types/cervical/patient/cervical-treatment-pdq. Accessed September 11, 2015.

4. Monk BJ, Sill MW, McMeekin DS, Cohn DE, Ramondetta LM, Boardman CH, Benda J and Cella D: Phase III trial of four cisplatin-containing doublet combination in stage IVB, recurrent or persistent cervical carcinoma: A gynecologic oncology group study. J Clin Oncol 27: 4649-4655, 2009.

5. Thigpen JT: The role of chemotherapy in the management of carcinoma of the cervix. Cancer J 9: 425-432, 2003.
6. Tattersall $\mathrm{MH}$, Ramirez $\mathrm{C}$ and Coppleson $\mathrm{M}$ : A randomized trial of adjuvant chemotherapy after radical hysterectomy in stage Ib-IIa cervical cancer patients with pelvic lymph node metastasis. Gynecol Oncol 46: 176-181, 1992.

7. Takeshima N, Umayahara K, Fujiwara K, Hirai Y, Takizawa K and Hasumi K: Treatment results of adjuvant chemotherapy after radical hysterectomy for intermediate-and high-risk stage IB-IIA cervical cancer. Gynecol Oncol 103: 618-622, 2006.

8. Lahousen M, Haas J, Pickel H, Hackl A, Kurz C, Ogris H, Stummoll W and Winter R: Chemotherapy versus radiotherapy versus observation for high-risk cervical carcinoma after radical hysterectomy: A randomized, prospective, multicenter trial. Gynecol Oncol 73: 196-201, 1999.

9. Kato R, Hasegawa K, Achiwa Y, Okamoto H, Torii Y, Oe S and Udagawa Y: Predicting nedaplatin sensitivity of cervical cancer using the histoculture drug response assay. Eur J Gynaecol Oncol 32: 381-386, 2011.

10. Yamamoto K, Kokawa K, Nishimura R, Hasegawa K, Konishi I, Saji F, Nishida M, Noguchi H and Takizawa K: Phase I study of combination chemotherapy with irinotecan hydrochloride and nedaplatin for cervical squamous cell carcinoma: Japanese gynecologic oncology group study. Oncol Rep 21: 1005-1009, 2009.

11. Watanabe Y, Nakai H, Etoh T, Kanemura K, Tsuji I, Ishizu A and Hoshiai H: Feasibility study of docetaxel and nedaplatin for recurrent squamous cell carcinoma of the uterine cervix. Anticancer Res 28: 2385-2388, 2008.

12. Detre S, Saclani Jotti G and Dowsett M: A ‘quickscore' method for immunohistochemical semiquantitation: Validation for oestrogen receptor in breast carcinomas. J Clin Pathol 48: 876-878, 1995.

13. Kim MK, Cho KJ, Kwon GY, Park SI, Kim YH, Kim JH, Song HY, Shin JH, Jung HY, Lee GH, et al: ERCC1 predicting chemoradiation resistance and poor outcome in oesophageal cancer. Eur J Cancer 44: 54-60, 2008.

14. Vescio RA, Connors KM, Kubota T and Hoffman RM: Correlation of histology and drug response of human tumors grown in negative-state three-dimensional histoculture and in nude mice. Proc Natl Acad Sci USA 88: 5163-5166, 1991.

15. Hoffman RM: In vitro assay for chemotherapy sensitivity. Crit Rev Oncol Hematol 15: 99-111, 1993.

16. Ohie S, Udagawa Y, Kozu A, Komuro Y, Aoki D, Nozawa S, Moossa AR and Hoffman RM: Cisplatin sensitivity of ovarian cancer in the histoculture drug response assay correlates to clinical response to combination chemotherapy with cisplatin, doxorubicin and cyclophosphamide. Anticancer Res 20: 2049-2054, 2000.

17. Yoshimasu T, Ohta F, Oura S, Tamaki T, Shimizu Y, Naito K, Kiyoi M, Hirai Y, Kawago M and Okamura Y: Histoculture drug response assay for gefitinib in non-small-cell lung cancer. Gen Thorac Cardiovasc Surg 57: 138-143, 2009.

18. Fujita Y, Hiramatsu M, Kawai M, Nishimura H, Miyamoto A and Tanigawa N: Histoculture drug response assay predicts the postoperative prognosis of patients with esophageal cancer. Oncol Rep 21: 499-505, 2009.

19. Furukawa T, Kubota T and Hoffman RM: Clinical application of the histoculture drug response assay. Clin Cancer Res 1: 305-311, 1995.

20. Furukawa T, Kubota T, Tanino H, et al: Chemosensitivity of breast cancer lymph node metastasis compared to the primary tumor from individual patients tested in the histoculture drug response assay. Anticancer Res 20: 3657-3658, 2000.

21. Tanino H, Oura S, Hoffman RM, et al: Acquisition of multidrug resistance in recurrent breast cancer demonstrated by the histoculture drug response assay. Anticancer Res 21: 4083-4086, 2001.

22. Hirano Y, Kageyama S, Ushiyama T, Suzuki K and Fujita K: Clinical usefulness of chemotherapy based on an in vitro chemosensitivity test in urothelial cancer patients. Anticancer Res 21: 4061-4066, 2001.

23. Singh B, Li R, Xu LI, et al: Prediction of survival in patients with head and neck cancer using the histoculture drug response assay. Head Neck 24: 437-442, 2002.

24. Morioka H, Yabe H, Morii T, Yamada R, Kato S, Yuasa S and Yano T: In vitro chemosensitivity of human soft tissue sarcoma. Anticancer Res 21: 4147-4151, 2001.

25. Nakata S, Aoki D, Ohie S, Horiguchi M, Suzuki N, Kanasugi M, Susumu N, Udagawa Y and Nozawa S: Chemosensitivity testing of ovarian cancer using the histoculture drug response assay: Sensitivity to cisplatin and clinical response. Int J Gynecol Cancer 15: 445-452, 2005. 
26. Kanasugi M, Aoki D, Suzuki N, Susumu N, Nakata S, Horiguchi M, Udagawa Y and Nozawa S: Sensitivity to cisplatin determined by the histoculture drug response assay and clinical response of endometrial cancer. Int J Gyenecol Cancer 16 : 409-415, 2006

27. Bonetti A, Zaninelli M, Rodella S, Molino A, Sperotto L, Piubello Q, Bonetti F, Nortilli R, Turazza M and Cetto GL: Tumor proliferative activity and response to first-line chemotherapy in advanced breast carcinoma. Breast Cancer Res Treat 38: 289-297, 1996.

28. O'Reilly SM, Camplejohn RS, Rubens RD and Richards MA: DNA flow cytometry and response to preoperative chemotherapy for primary breast cancer. Eur J Cancer 28: 681-683, 1992.

29. Sultana H, Kigawa J, Kanamori Y, Itamochi H, Oishi T, Sato S, Kamazawa S, Ohwada M, Suzuki M and Terakawa N: Chemosensitivity and p53-Bax pathway-mediated apoptosis in patients with uterine cervical cancer. Ann Oncol 14: 214-219, 2003.

30. Costa S, Terzano P, Santini D, Ceccarelli C, Martoni A, Angelelli B, Panetta A, Bovicelli A, Cristiani P, Lipponen P, et al: Neoadjuvant chemotherapy in cervical carcinoma: Regulators of cell cycle, apoptosis, and proliferation as determinants of response to therapy and disease outcome. Am J Clin Pathol 116: 729-737, 2001.

31. Righetti SC, Della Torre G, Pilotti S, Ménard S, Ottone F, Colnaghi MI, Pierotti MA, Lavarino C, Cornarotti M, Oriana S, et al: A comparative study of $\mathrm{p} 53$ gene mutations, protein accumulation and response to cisplatin-based chemotherapy in advanced ovarian carcinoma. Cancer Res 56: 689-693, 1996.

32. Sato S, Kigawa J, Minagawa Y, Okada M, Shimada M, Takahashi M, Kamazawa S and Terakawa N: Chemosensitivity and p53-dependent apoptosis in epithelial ovarian carcinoma. Cancer 86: 1307-1313, 1999.

33. Lu X and Feki A: Phenotypic features with p53 alterations related to human papillomavirus and prognostic evaluation in cervical cancer. Int J Gynecol Cancer 16: 708-717, 2006.

34. Soussi T, Dehouche K and Béroud C: P53 website and analysis of p53 gene mutations in human cancer: forging a link between epidemiology and carcinogenesis. Hum Mutat 15: 105-113, 2000.

35. Kraiss S, Spiess S, Reihsaus E and Montenarh M: Correlation of metabolic stability and altered quaternary structure of oncoprotein p53 with cell transformation. Exp Cell Res 192: 157-164, 1991.

36. Banin S, Moyal L, Shieh S, Taya Y, Anderson CW, Chessa L, Smorodinsky NI, Prives C, Reiss Y, Shiloh Y and Ziv Y: Enhanced phosphorylation of p53 by ATM in response to DNA damage. Science 281: 1674-1677, 1998.

37. Hirao A, Kong YY, Matsuoka S, et al: DNA damage-induced activation of $\mathrm{p} 53$ by the checkpoint kinase Chk2. Science 287 1824-1827, 2000

38. Reed JC: Bcl-2 and the regulation of programmed cell death. J Cell Biol 124: 1-6, 1994.

39. Pillai MR, Jayaprakash PG and Nair MK: Bcl-2 immunoreactivity but not $\mathrm{p} 53$ accumulation associated with tumour response to radiotherapy in cervical carcinoma. J Cancer Res Clin Oncol 125: 55-60, 1999

40. Rajkumar T, Rajan S, Baruah RK, Majhi U, Selvaluxmi G and Vasanthan A: Prognostic significance of Bcl-2 and p53 protein expression in stage IIB and IIIB squamous cell carcinoma of the cervix. Eur J Gynaecol Oncol 19: 556-560, 1998

41. Wootipoom V,Lekhyananda N,Phungrassami T, Boonyaphiphat $P$ and Thongsuksai P: Prognostic significance of Bax, Bcl-2 and p53 expressions in cervical squamous cell carcinoma treated by radiotherapy. Gynecol Oncol 94: 636-642, 2004.

42. Pezzella F, Turley H, Kuzu I, et al: Bcl-2 protein in non-small cell lung carcinoma. N Engl J Med 329: 690-694, 1993.

43. Joensuu H, Pylkkänen L and Toikkanen S: Bcl-2 protein expression and long-term survival in breast cancer. Am J Pathol 145: 1191-1198, 1994.

44. Diebold J, Baretton G, Felchner M, et al: Bcl-2 expression, p53 accumulation, and apoptosis in ovarian carcinoma. Am J Clin Pathol 105: 341-349, 1996.

45. Crawford RA, Caldwell C, Iles RK, et al: Prognostic significance of the bcl-2 apoptotic family of proteins in primary and recurrent cervical cancer. Br J Cancer 78: 210-214, 1998.

46. Itoi T, Yamana K, Bilim V, Takahashi K and Tomita F: Impact of frequent bcl-2 expression on better prognosis in renal cell carcinoma patients. Br J Cancer 90: 200-205, 2004

47. Saito T, Takehara M, Tanaka R, Lee R, Horie M, Wataba K, Ito E and Kudo R: Correlation between responsiveness of neoadjuvant chemotherapy and apoptosis-associated proteins for cervical adenocarcinoma. Gynecol Oncol 92: 284-292, 2004.
48. Munakata S, Watanabe O, Ohashi $\mathrm{K}$ and Morino H: Expression of Fas ligand and bcl-2 in cervical carcinoma and their prognostic significance. Am J Clin Pathol 123: 879-885, 2005.

49. Padovan P, Salmaso R, Marchetti M and Padovan R: Prognostic value of bcl-2, p53 and $\mathrm{Ki}-67$ in invasive squamous carcinoma of the uterine cervix. Eur J Gynecol Oncol 21: 267-272, 2000.

50. Mukherjee G, Freeman A, Moore R, Kumaraswamy, Devi KU, Morris LS, Coleman N, Dilworth S, Prabhakaran PS and Stanley MA: Biologic factors and response to radiotherapy in carcinoma of the cervix. Int J Gynecol Cancer 11: 187-193, 2001.

51. Gown AM and Willingham MC: Improved detection of apoptotic cells in archival paraffin sections: Immunohistochemistry using antibodies to cleaved caspase 3. J Histochem Cytochem 50: 449-454, 2000

52. Levine EL, Renehan A, Gossiel R, Davidson SE, Roberts SA, Chadwick C, Wilks DP, Potten CS, Hendry JH, Hunter RD, et al: Apoptosis, intrinsic radiosensitivity and prediction of radiotherapy response in cervical carcinoma. Radiother Oncol 37: 1-9, 1995.

53. Levine EL, Davidson SE, Roberts SA, Chadwick CA, Potten CS and West CM: Apoptosis as predictor of response to radiotherapy in cervical carcinoma. Lancet 344: 472, 1994.

54. Kim JY, Cho HY, Lee KC, Hwang YJ, Lee MH, Roberts SA and $\mathrm{Kim} \mathrm{CH}$ : Tumor apoptosis in cervical cancer: Its role as a prognostic factor in 42 radiotherapy patients. Int J Cancer 96: 305-312, 2001.

55. Tomozawa S, Tsuno NH, Sunamio E, Hatano K, Kitayama J, Osada T, Saito S, Tsuruo T, Shibata Y and Nagawa H: Cyclooxygenase-2 overexpression correlates with tumor recurrence, especially haematogenous metastasis of colorectal cancer. Br J Cancer 83: 324-328, 2000.

56. Madaan S, Abel PD, Chaudhary KS, Hewitt R, Stott MA, Stamp GW and Lalani EN: Cytoplasmic induction and overexpression of cyclooxygenase- 2 in human prostate cancer: Implication for prevention and treatment. BJU Int 86: 736-741, 2000.

57. Hwang D, Skollard D, Byerne J and Levine E: Expression of Cyclooxygenase- 1 and cyclooxygenase- 2 in human breast cancer. J Natl Cancer Inst 90: 455-460, 1998

58. Achiwa H, Yatabe Y, Hida T, Kuroishi T, Kozaki K, Nakamura S, Ogawa M, Sugiura T, Mitsudomi T and Takahashi T: Prognostic significance of elevated cyclooxygenase-2 expression in primary resected lung adenocarcinomas. Clin Cancer Res 5: 1001-1005, 1999.

59. Sheehan KM, Sheahan K, O'Donoghue DP, MacSweeney F, Conroy RM, Fitzgerald DJ and Murray FE: The relationship between Cyclooxygenase-2 expression and colorectal cancer. JAMA 282: 1254-1257, 1999.

60. Liu XH, Yao S, Kirschenbaum A and Levine AC: NS398, a selective cyclooxygenase-2 inhibitor, induces apoptosis and down regulation bcl-2 expression in LNCaP cells. Cancer Res 58: 4254-4249, 1998.

61. Ferrandina G, Lauriola L, Distefana MG, Zannoni GF, Gessi M, Legge F, Maggiano N, Mancuso S, Capelli A, Scambia G and Ranelletti FO: Increased cyclooxygenase-2 expression is associated with chemotherapy resistance and poor survival in cervical cancer patients. J Clin Oncol 20: 973-981, 2002.

62. de Laat WL, Appeldoorn E, Jaspers NG and Hoeijmakers JH: DNA structural elements required for ERCC1-XPF endonuclease activity. J Biol Chem 273: 7835-7842, 1998.

63. Lord RV, Brabender J, Gandara D, Alberola V, Camps C, Domine M, Cardenal F, Sánchez JM, Gumerlock PH, Tarón M, et al: Low ERCC1 expression correlates with prolonged survival after cisplatin plus gemcitabine chemotherapy in non-small cell lung cancer. Clin Cancer Res 8: 2286-2291, 2002.

64. Azuma K, Komohara Y, Sasada T, Terazaki Y, Ikeda J, Hoshino T, Itoh K, Yamada A and Aizawa H: Excision repair cross-complementation group 1 predicts progression-free and overall survival in non-small cell lung cancer patients treated with platinum-based chemotherapy. Cancer Sci 98: 1336-1343, 2007.

65. Olaussen KA, Dunant A, Fouret P, et al: DNA repair by ERCC1 in non-small-lung cancer and cisplatin-based adjuvant chemotherapy. N Engl J Med 355: 983-991, 2006.

66. Metzger R, Leichman CG, Danenberg KD, et al: ERCC1 mRNA levels complement thymidylate synthase mRNA levels in predicting response and survival for gastric cancer patients receiving combination cisplatin and fluorouracil chemotherapy. J Clin Oncol 16: 309-316, 1998.

67. Kim MK, Cho KJ, Kwan GY, et al: ERCC1 predicting chemoradiation resistance and poor outcome in oesophageal cancer. Eur J Cancer 44: 54-60, 2008. 
68. Bellmunt J, Paz-Ares L, Cuello M, Cecere FL, Albiol S, Guillem V, Gallardo E, Carles J, Mendez P, de la Cruz JJ, et al: Gene expression of ERCC1 as a novel prognostic marker in advanced bladder cancer patients receiving cisplatin-based chemotherapy. Ann Oncol 18: 522-528, 2007.

69. Steffensen KD, Waldstrøm M and Jakobsen A. The relationship of platinum resistance and ERCC1 protein expression in epithelial ovarian cancer. Int J Gynecol Cancer 19: 820-825, 2009.

70. Scheil-Bertram S, Tylus-Schaaf P, du Bois A, Harter P, Oppitz M, Ewald-Riegler N and Fisseler-Eckhoff A: Excision repair cross-complementation group 1 protein overexpression as a predictor of poor survival for high-grade serous ovarian adenocarcinoma. Gynecol Oncol 119: 325-331, 2010.

71. Park JS, Jeon EK, Chun SH, Won HS, Lee A, Hur SY, Lee KH, Bae SN, Yoon SC and Hong SH: ERCC1 (excision repair cross-complementation group 1) expression as a predictor for response of neoadjuvant chemotherapy for FIGO 2B uterine cervix cancer. Gynecol Oncol 120: 275-279, 2011.
72. Hasegawa K, Kato R, Torii Y, Ichikawa R, Oe S and Udagawa Y: The relationship between ERCC1 expression and clinical outcome in patients with FIGO stage I to stage II uterine cervical adenocarcinoma. Int J Gynecol Cancer 21: 1479-1485, 2011.

73. Costa S, Terzano P, Bovicelli A, Martoni A, Angelelli B, Santini D, Ceccarelli C, Lipponen P, Erzén M, Syrjänen S and Syrjänen K: $\mathrm{CD} 44$ isoform $6(\mathrm{CD} 44 \mathrm{v} 6)$ is a prognostic indicatior of the response to neoadjuvant chemotherapy in cervical cancer. Gynecol Oncol 80: 67-73, 2001.

74. Chung HH, Kim MK, Kim JW, Park NH, Song YS, Kang SB and Lee HP: XRCC1 R399Q polymorphism is associated with response to platinum-based neoadjuvant chemotherapy in bulky cervical cancer. Gynecol Oncol 103: 1031-1037, 2006.

75. Faried LS, Faried A, Kanuma T, Sano T, Nakazato T, Tamura T, Kuwano H and Minegishi T: Predictive and prognostic role of activated mammalian target of rapamycin in cervical cancer treated with cisplatin-based neoadjuvant chemotherapy. Oncol Rep 16: 57-63, 2006. 